\title{
Stem vs non-stem cell origin of colorectal cancer
}

\author{
DJ Huels ${ }^{1}$ and OJ Sansom ${ }^{\star}, 1$ \\ ${ }^{1}$ CR-UK Beatson Institute for Cancer Research, Garscube Estate, Glasgow G61 1BD, UK
}

Colorectal cancer (CRC) is one of the most common cancers in the western world and is characterised by deregulation of the Wnt signalling pathway. Mutation of the adenomatous polyposis coli (APC) tumour suppressor gene, which encodes a protein that negatively regulates this pathway, occurs in almost $80 \%$ of CRC cases. The progression of this cancer from an early adenoma to carcinoma is accompanied by a well-characterised set of mutations including KRAS, SMAD4 and TP53. Using elegant genetic models the current paradigm is that the intestinal stem cell is the origin of CRC. However, human histology and recent studies, showing marked plasticity within the intestinal epithelium, may point to other cells of origin. Here we will review these latest studies and place these in context to provide an up-to-date view of the cell of origin of CRC.

We first need to briefly introduce normal intestinal homeostasis and stem cells (for a recent in depth review see Vermeulen and Snippert, 2014).The intestinal epithelium has a remarkable capacity for self-renewal; every 4-5 days, the majority of the epithelial cells within the gut are replaced. The intestinal stem cells (ISCs), which are responsible for the epithelial renewal, reside at the bottom of the crypt (Figure 1). The immediate daughter cells of the stem cells proliferate for a finite number of times themselves before fully differentiating. These transit amplifying (TA) cells are the major producer of the epithelial cells and are situated directly above the stem cells (Figure 1A). In an intestinal crypt there are 5-16 ISCs per crypt and roughly 120-150 TA cells. Only few specialised cells (e.g., tuft cells, neuroendocrine cells and Paneth cells) live longer than the average 4-5 days. This rapid turnover of the intestinal epithelium led to the assumption that the long-lived ISCs are the most likely cell of origin for tumourigenesis.

\section{PLASTICITY OF STEM CELL IN THE INTESTINE}

The ISCs at the bottom of the crypt are defined by high Wnt activity, a characteristic they share with CRC tumour cells. In recent years, studies have shown that there is not just a single defined ISC pool in the intestine, but rather cells in the stem cell niche that can replace and compensate each other and therefore can also change their expression profile. There are at least two functional different ISCs, the crypt base columnar cells (CBCs) and the slow-proliferating label-retaining cells. With the discovery of the ISC marker LGR5, it was shown that these CBCs are the main pool of actively cycling ISCs (Barker et al, 2007).

Other ISC markers with a broader expression at the base of the crypt have been discovered that label more than the Lgr5 + ve cells, for example, Lrig1 (Powell et al, 2012), Hoxp1, Bmil and mTert (Montgomery et al, 2011). Although protein expression data have suggested these to be tightly located (i.e., at position +4 ), RNA expression data have placed Hoxp1 and Bmil relatively broadly at the base of the crypt (Sangiorgi and Capecchi, 2008; Muñoz et al, 2012).

Given that this set of markers are expressed in a wider range of cells at the base of the crypt helps to explain the studies that show that LGR5 + ve cells are dispensable for homeostasis of the intestine. Here LGR5 + ve cells were killed using diphtheria toxin, but the intestinal homeostasis was unperturbed (Tian et al, 2011). However, following radiation, the LGR5 + ve cell-depleted intestine was unable to recover (Metcalfe et al, 2014), showing that in certain circumstances the other cells in the stem cell niche are not able to compensate this loss.

As expression data have placed many ISC markers rather broadly at the base of the crypt, a recent study has taken a functional approach using in vivo imaging to define stem cell capacity at the base of the crypt. Ritsma et al (2014) showed there are about 16 LGR + ve cells in a crypt, some of which are located towards the centre of the crypt and others which are higher up, located at the border of the crypt base. Importantly, the probability of these centre and border stem cells to stay in the crypt over time and function as a stem cell was different. The 'central cells' were more likely to retain stem cell capacity compared with the 'border cells'.

*Correspondence: Professor O Sansom; E-mail: o.sansom@beatson.gla.ac.uk

Received 22 December 2014; revised 7 May 2015; accepted 13 May 2015;

published online 25 June 2015

(c) 2015 Cancer Research UK. All rights reserved 0007-0920/15

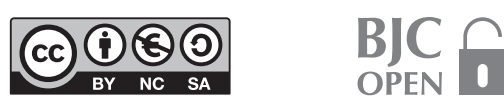




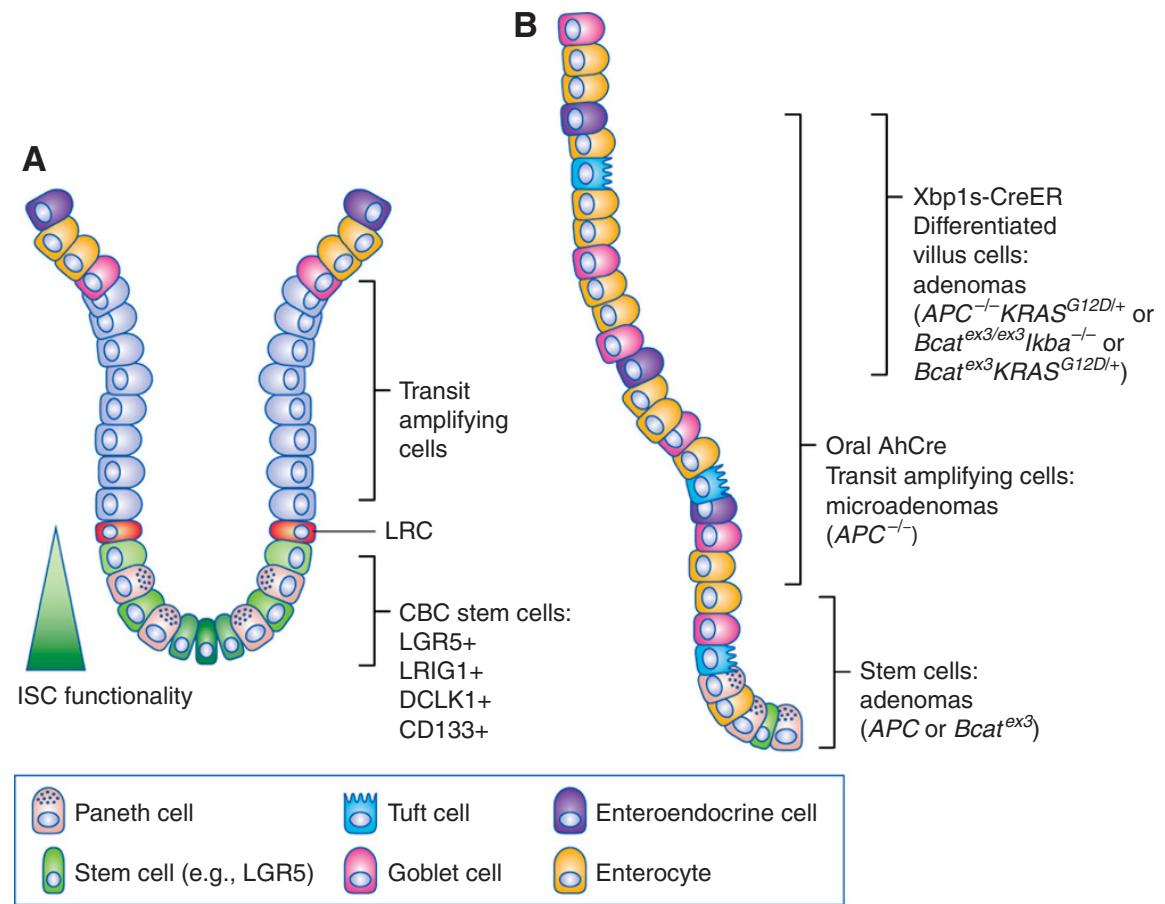

Figure 1. Methods to induce adenoma formation in stem cells and differentiated cells. (A) Overview of a crypt in the small intestine. The crypt base columnar (CBC) cells are located at the bottom of the crypt in between the Paneth cells. In addition to the expression of several stem cell markers, the functionality of the intestinal stem cell (ISC) is determined by its location, with the 'centre' ISC having the highest ISC functionality. (B) The expression of specific stem cell markers has been used to induce cre-driven recombination in ISCs, leading to adenoma formation, either by loss of Apc or Bcat ${ }^{\text {ex } 3}$ mutation. Oral administration of low-dose $\beta$-naphthoflavone has been used to induce AhCre-dependent Apc loss in cells above the crypt base, resulting in formation of microadenomas. Recombination in differentiated villus cells only resulted in adenomas when Apc loss or Bcat ${ }^{e \times 3}$ mutation was combined with Kras mutation or NFKB activation (villus purification in VilCre ${ }^{E R}$ mice or Xbp1sCre ${ }^{E R}$ ).

This was not absolute as there is a constant transfer of cells between these two regions. Therefore the functionality of an ISC is defined by its position (as has been previously speculated (Sansom and Näthke, 2013)) rather than the expression of a specific protein marker.

Label-retaining studies using radioactive thymidine precursor (Potten et al, 1974) and recently by H2B-GFP/-YFP(Roth et al, 2012; Buczacki et al, 2013) lineage tracing have identified that there are a set of long-lived cells within the intestine that can act as stem cells as well and repopulate the intestine post damage. These cells express secretory markers and can be thought of as early progenitor cells, which fall back into the stem cell niche following damage and potentially dedifferentiate to develop full stem cell potential. In a complementary manner, cells that express Dll1 in the crypt mark secretory progenitors, which do not normally act as stem cells, but post damage can repopulate the crypt (Van Es et al, 2012).

Taken together these studies show that the normal intestine has great plasticity and non-stem cells could dedifferentiate to produce a stem cell-like phenotype, which is able to repopulate the intestine. This suggests that there may also be an increased repertoire of cells that could act as the cell of origin for colorectal cancer.

\section{INITIATING MUTATIONS IN CRC}

In 1990, it was postulated that CRC was caused by the accumulation of mutations that drive tumour initiation and then progression (Fearon and Vogelstein, 1990). Indeed, it was postulated that this process could take over 10 years (Beerenwinkel et al, 2007). Loss of the APC gene is the likely initiating mutation followed by additional mutations in KRAS, TGFB, PI3 Kinase and TP53 signalling pathway components. It is interesting to note when these mutations are modelled in the murine intestinal epithelium, apart from Apc loss, the other mutations alone have very minor impact on intestinal homeostasis and only yield tumours at very long latencies (Kras, Tp53, Pten). However, loss of $A p c$ leads to a rapid Wnt deregulation and acquisition of a crypt-progenitor cell phenotype in the small intestine and colon (Sansom et al, 2004).

\section{ACQUISITION OF MUTATIONS}

How do cells acquire mutations and what are the direct consequences? It is generally believed that the main source for mutations in the intestine is due to DNA replication errors and carcinogenic exposure. Given the high proliferation of the TA cells and the more restricted zone of proliferation of the ISCs, the TA cells are more prone to acquire a mutation. However, as long as the cell migration is not perturbed, these cells would be shed from the intestine within 3-4 days. Given the relatively mild phenotypes arising from mutation of most of the major tumour suppressors and oncogenes, a TA cell with a single mutation would be lost within a couple of days. The short lifespan of these proliferating cells reduces the risk of tumour initiation.

An additional mechanism to prevent accumulation of mutated cells in the crypt is the neutral drift of the ISCs. Until recently it was believed that ISCs divide by asymmetric cell division, which means an ISC gives rise to one TA cell and one ISC. Instead, the ISC division follows a principle of random replacement of ISCs, a process called 'neutral drift' (Lopez-Garcia et al, 2010; Snippert et al, 2010). This means that a single ISC in a crypt can be replaced by any of the other ISCs in the crypt. In a scenario with 5 functional ISCs, a marked wild-type stem cell has a 1/5 (20\%) chance to populate the whole crypt and replace all the other ISCs. 
In an elegant study by Vermeulen et al (2013) the consequences of oncogenic mutations on ISC fitness has been studied. If one ISC acquires a neutral mutation it has a high risk of being replaced by a normal stem cell within the crypt. The probability for an $A p c$ mutation, for example, to become fixed, that is, to populate the whole crypt is $42 \%$ ( $P_{\mathrm{R}}=0.62, N=5$ stem cells), which means in the majority of cases the mutated cell will be replaced by one of its wild-type stem cell neighbours and will be consequently lost. The advantage of a Kras mutation ( $\operatorname{Kras}^{G 12 D}$ ) to populate the whole crypt is even higher (about 72\%), which was confirmed in another study (Snippert et al, 2014). Although these studies have not taken into account the different positions of the tracked stem cell at start of the observation, it demonstrates the mutation itself has a major impact on the stem cell fitness.

Furthermore it shows that even if a stem cell acquires a mutation, there is a high chance that the cell will be lost, even if it has an advantage on the stem cell fitness. This might explain why CRC takes years to develop, even in patients with a genetic predisposition (germline $A P C^{m u t /+}$ ) to familiar adenomatous polyposis (FAP) disease.

\section{STEM CELLS AS CELL OF ORIGIN}

The discovery of expression markers for ISCs has enabled functional approaches to be used to test whether they can act as a cell of origin for intestinal tumourigenesis. Several studies (see Table 1) have shown that Apc deletion specifically in Lgr5+ (Barker et al, 2009), Lrig + (Powell et al, 2012, 2014), CD133/ Prominin1 (Zhu et al, 2009) and other cells can provoke rapid adenoma formation. Bmil + ve cells were also able to form small intestinal adenomas when an activating $\beta$-catenin mutation was targeted to these cells (Sangiorgi and Capecchi, 2008). Thus it appears that Wnt activation in the stem cells is sufficient for adenoma formation in the mouse. One important caveat is that most of these approaches have been limited to the generation of intestinal adenomas (most of which form in the small intestine).

\section{NON-STEM CELL ROUTES}

In contrast to this plethora of studies showing adenomas originating from stem cells, there is a more limited literature on

\begin{tabular}{|c|c|c|c|c|}
\hline Targeted cells & Cre & Mutation & $\begin{array}{l}\text { Tumouri- } \\
\text { genesis }\end{array}$ & Reference \\
\hline \multirow[t]{5}{*}{ Stem cells } & Lgr5 & $A p c^{-1-}$ & Yes & $\begin{array}{l}\text { (Barker et al, } \\
\text { 2009) }\end{array}$ \\
\hline & $\begin{array}{l}\text { CD133 } \\
\text { (Prom1) }\end{array}$ & Ctnnb $1^{\mathrm{ex} 3 /+}$ & Yes & $\begin{array}{l}\text { (Zhu et al, } \\
\text { 2009) }\end{array}$ \\
\hline & Bmi1 & Ctnnb1 $1^{\mathrm{ex} 3 /+}$ & Yes & $\begin{array}{l}\text { (Sangiorgi and } \\
\text { Capecchi, } \\
\text { 2008) }\end{array}$ \\
\hline & Dclk1 & $A p c^{-1-}$ & $\begin{array}{l}\text { Only with } \\
\text { inflammation }\end{array}$ & $\begin{array}{l}\text { (Westphalen } \\
\text { et al, 2014) }\end{array}$ \\
\hline & Lrig1 & $\mathrm{Apc}^{+/-}$ & Yes & $\begin{array}{l}\text { (Powell et al, } \\
\text { 2012) }\end{array}$ \\
\hline \multirow[t]{2}{*}{ Transit amplifying cells } & $\begin{array}{l}\text { AhCre (low } \\
\text { oral dose) }\end{array}$ & $A p c^{-1-}$ & $\begin{array}{l}\text { Yes, but mainly } \\
\text { microadenomas }\end{array}$ & $\begin{array}{l}\text { (Barker et al, } \\
\text { 2009) }\end{array}$ \\
\hline & Xbp1 & Ctnnb1 $1^{e \times 3 /+}$ & No & $\begin{array}{l}\text { (Schwitalla } \\
\text { et al, 2013) }\end{array}$ \\
\hline \multirow{2}{*}{$\begin{array}{l}\text { Differentiated villus cells } \\
\text { (via in vitro purification } \\
\text { of villi cells) }\end{array}$} & VilCre ${ }^{E R}$ & $A p c^{-1-}$ & No & \multirow[t]{2}{*}{$\begin{array}{l}\text { (Schwitalla } \\
\text { et al, 2013) }\end{array}$} \\
\hline & & $\begin{array}{l}\mathrm{Apc}^{-/-} \\
\operatorname{Kras}^{\mathrm{G12D/+}}\end{array}$ & Yes & \\
\hline
\end{tabular}

tumours developing via non-stem cells routes in the mouse. This is in part owing to the rapid turnover of these cells (one would predict from Cre induction to gene and protein turnover about $48 \mathrm{~h}$ ).

Our initial studies to delete $A p c$ in the non-stem cell compartment using an oral dose of Cre inducer to spare the crypt stem cells led to the production of a number of small lesions that were retained within the intestinal epithelium. These however did not form tumours rapidly and even at 200 days post induction, many predominantly small lesions remained, though rarely one would progress to an adenoma. This was the first study to make a qualitative comparison between stem cells and TA cells as the cell of origin. Although the Lgr5 + ve cells were much more efficient in adenoma formation, it is important to note that the mutated TA cells were not lost and the microscopic lesions found after 280 days were high in nuclear $\beta$-catenin (Barker et al, 2009) (Figure 1B).

Deregulation of Wnt signalling by loss of $A p c$ in Dclk1 + tuft cells (that do not have stem cell characteristics (Nakanishi et al, 2012)) was not able to induce tumourigenesis. However, when these APC-deficient tuft cells where challenged with dextran sulphate sodium to induce colitis, even 3 months after induction, they formed colonic tumours (Westphalen et al, 2014). This suggests that Apc loss in a non-stem cell population could initiate tumourigenesis but would need extra events (e.g., inflammation) to progress to an adenoma.

These studies suggested that if cells acquire mutations and persist, additional events (e.g., mutations or inflammation) could then lead to adenoma progression.

The ability to 'dedifferentiate' and the link with pathways involved in inflammation was tested in more depth by Greten and colleagues. Activation of the NFKB pathway could provoke cryptlike structures in the villus and there was strong cooperation of Wnt pathway and NFKB pathway activation for tumour initiation. To test whether one of the reasons for increased tumour initiation was due to an expanded cell of origin population they used the Xbps1-CreER to target differentiated cells in the intestine. Xbps1 is an ER stress protein that is not expressed in stem cells of the intestine and thus allows recombination in more differentiated cells of the epithelium. Using this Cre, an activating $\beta$-catenin mutation was unable to transform the intestinal epithelium. However, when a $\beta$-catenin mutation was combined with increased NFKB signalling, tumours could be formed (Schwitalla et al, 2013).

Importantly, the same study showed that one of the consequences of a $\mathrm{Kras}^{G 12 D}$ mutation in CRC was to activate NFKB signalling and hence Kras could also initiate tumourigenesis in differentiated cells when combined with Wnt pathway activation owing to loss of Apc.

Recently, it was shown that also changes in the intestinal microenvironment can initiate tumour formation in nonstem cells (Davis et al, 2014). Hereditary mixed polyposis syndrome (HMPS) is caused by aberrant expression of the bone morphogenetic protein (BMP) antagonist 'GREM1'. This BMP antagonist is usually expressed by mesenchymal cells, but owing to a gene duplication, in these patients, it is expressed by intestinal epithelial cells. The authors generated a mouse model with aberrant expression of GREM1 in the intestinal epithelium, which resulted in the formation of crypt structures in the differentiated villus compartment, similar to human HMPS. These crypt structures proliferated and were able to acquire additional mutations, which led to intestinal neoplasia.

Taken together, these studies showed that targeting Wnt pathway activation alone in non-stem cells was not sufficient to drive adenoma formation. However, additional mutations, activation of inflammatory pathways or changes in the microenvironment were able to increase the pool of cell of origin to non-stem cells. 


\section{'TOP-DOWN VS BOTTOM-UP' DEBATE}

Thus, far this review has been restricted to discussion of small intestinal adenoma formation in mouse models, so what of the human CRC? Obviously the cre-lox lineage tracing experiments performed in mice cannot be done in humans, but naturally occurring methylation or mitochondrial mutations can be used to study the fate of stem cells in human samples. Already in 2001 Shibata and coworkers (Yatabe et al, 2001) indicated a model in which several stem cells per crypt are present and are constantly replaced. More recently Baker et al (2014) were able to study clonal advantage of stem cells in humans by tracking stem cells with unique somatic mitochondrial mutation. Here the authors confirm the neutral drift theory in humans and show that the number of functional stem cells in a human colonic crypt is similar to the number in mice (5-6).

However, the histology of human CRC and early lesions in patients with FAP had triggered a debate over the cell of origin of CRC. This was owing to the observation that dysplastic cells are mainly found at the luminal surface of the colon with normal crypt cells underneath. When the lab of Bert Vogelstein microdissected several spontaneous adenomas they found that only cells at the top of the crypt had mutations in $A P C$, whereas the underlying crypts with their respective stem cells revealed no such mutations. This led to the so called 'top-down' model, where tumour initiation starts at the top of the crypt and then spreads laterally and consequently also downwards towards the normal crypt (Shih et al, 2001).

In contrast, it has been observed in patients with familial predispositions in the APC gene, the dysplastic cells often occupy entire single crypts (monocryptal adenoma), which can also be found, but rarely, in spontaneous colorectal adenomas. This 'bottom-up' model would predict that the stem cell at the bottom of the crypt is the cell of tumour initiation and populates the entire crypt (Preston et al, 2003).

\section{UNANSWERED POINTS/CONSIDERATION}

After the lessons from the induced pluripotent stem cells, it is perhaps unsurprising that differentiated cells in the intestine could form a tumour if given enough oncogenic events. The key question is, could it happen in patients? From the discussion of the rapid turnover of the intestinal epithelium, this already suggests a hierarchy of cells that would be able to be transformed. The likelihood of acquiring a mutation and giving rise to a phenotype in a cell that is differentiated is unlikely due to its stop in proliferation and short lifespan. However, a TA or a progenitor cell, which is about to undergo a number of cell divisions, would dilute out any remaining protein after mutation of the gene. If the mutation conferred a selective advantage that allowed a cell and its daughter cells to persist, then this could result in a potential cell of origin for cancer.

However, for a cell to gain three mutations, for example, biallelic loss of APC and a KRAS mutation would be highly unlikely. Instead one could imagine perhaps a model where an intestinal stem cell has a novel APC mutation which then due to drift (and an selective advantage) makes an entire crypt $A P C^{\text {mut } /+}$ throughout. One could then envisage a second mutation in a daughter cell that persists to form a microadenoma. Further mutations such as KRAS mutation could then drive bona fide tumour formation.

Another possibility is that certain mutations (e.g., KRAS or BRAF) would select for mutations in an inflammatory environment via a non-APC route of tumourigenesis (e.g., traditional serrated adenomas). These mutations could occur in long-lived differentiated cells and give rise to adenomas owing to a changed microenvironment.

One question still unclear is, what would be the clinical implications of a stem cell $v s$ a non-stem cell route for carcinogenesis? The mouse studies would suggest that a stem cell would need fewer mutations to form an adenoma and then would grow more rapidly. This might suggest that these tumours may acquire fewer mutations than ones in non-stem cells and therefore they may be more sensitive to treatment. It is interesting to note that the Hanahan lab identified signatures from human CRCs that could be compared with stem cells, TA cells and more differentiated cells, suggestive that tumours might keep the features of the cells from which they arose (Sadanandam et al, 2013). Although only a low number of patients were used there was some suggestion of potential prognostic and predictive potential of these signatures.

\section{CONCLUSION}

Overall, we show that the intestinal stem cells are defined by great plasticity. Wnt activation in the ISCs shows that they are very potent in initiating adenoma formation. The TA cells are also able to form adenomas, but not as potent as the stem cells. In addition, it became evident that even differentiated cells are able to initiate tumourigenesis but require additional events (i.e., mutations, inflammation or changes in the microenvironment). Therefore, we would conclude that the ISCs are the most potent cells for transformation, but certainly not the only possible cells of origin for colorectal cancer.

\section{REFERENCES}

Baker A-M, Cereser B, Melton S, Fletcher AG, Rodriguez-Justo M, Tadrous PJ, Humphries A, Elia G, McDonald SAC, Wright NA, Simons BD, Jansen M, Graham TA (2014) Quantification of crypt and stem cell evolution in the normal and neoplastic human colon. Cell Rep 8: 940-947.

Barker N, van Es JH, Kuipers J, Kujala P, van den Born M, Cozijnsen M, Haegebarth A, Korving J, Begthel H, Peters PJ, Clevers H (2007) Identification of stem cells in small intestine and colon by marker gene Lgr5. Nature 449: 1003-1007.

Barker N, Ridgway RA, van Es JH, van de Wetering M, Begthel H, van den Born M, Danenberg E, Clarke AR, Sansom OJ, Clevers H (2009) Crypt stem cells as the cells-of-origin of intestinal cancer. Nature 457: 608-611.

Beerenwinkel N, Antal T, Dingli D, Traulsen A, Kinzler KW, Velculescu VE, Vogelstein B, Nowak MA (2007) Genetic progression and the waiting time to cancer. PLoS Comput Biol 3: e225.

Buczacki SJA, Zecchini HI, Nicholson AM, Russell R, Vermeulen L, Kemp R, Winton DJ (2013) Intestinal label-retaining cells are secretory precursors expressing Lgr5. Nature 495: 65-69.

Davis H, Irshad S, Bansal M, Rafferty H, Boitsova T, Bardella C, Jaeger E, Lewis A, Freeman-Mills L, Giner FC, Rodenas-Cuadrado P, Mallappa S, Clark S, Thomas H, Jeffery R, Poulsom R, Rodriguez-Justo M, Novelli M, Chetty R, Silver A, Sansom OJ, Greten FR, Wang LM, East JE, Tomlinson I, Leedham SJ (2014) Aberrant epithelial GREM1 expression initiates colonic tumorigenesis from cells outside the stem cell niche. Nat Med 21(1): 62-70.

Fearon ER, Vogelstein B (1990) A genetic model for colorectal tumorigenesis. Cell 61: 759-767.

Lopez-Garcia C, Klein AM, Simons BD, Winton DJ (2010) Intestinal stem cell replacement follows a pattern of neutral drift. Science 330: 822-825.

Metcalfe C, Kljavin NM, Ybarra R, de Sauvage FJ (2014) Lgr5 + stem cells are indispensable for radiation-induced intestinal regeneration. Cell Stem Cell 14: 149-159.

Montgomery RK, Carlone DL, Richmond CA, Farilla L, Kranendonk MEG, Henderson DE, Baffour-Awuah NY, Ambruzs DM, Fogli LK, Algra S, Breault DT (2011) Mouse telomerase reverse transcriptase (mTert) expression marks slowly cycling intestinal stem cells. Proc Natl Acad Sci USA 108: 179-184. 
Muñoz J, Stange DE, Schepers AG, van de Wetering M, Koo B-K, Itzkovitz S, Volckmann R, Kung KS, Koster J, Radulescu S, Myant K, Versteeg R, Sansom OJ, van Es JH, Barker N, van Oudenaarden A, Mohammed S, Heck AJR, Clevers H (2012) The Lgr5 intestinal stem cell signature: robust expression of proposed quiescent ' + 4' cell markers. EMBO J 31: 3079-3091.

Nakanishi Y, Seno H, Fukuoka A, Ueo T, Yamaga Y, Maruno T, Nakanishi N, Kanda K, Komekado H, Kawada M, Isomura A, Kawada K, Sakai Y, Yanagita M, Kageyama R, Kawaguchi Y, Taketo MM, Yonehara S, Chiba T (2013) Dclk1 distinguishes between tumor and normal stem cells in the intestine. Nat Genet 45: 98-103.

Potten CS, Kovacs L, Hamilton E (1974) Continuous labelling studies on mouse skin and intestine. Cell Tissue Kinet 7: 271-283.

Powell AE, Vlacich G, Zhao Z-Y, McKinley ET, Washington MK, Manning HC, Coffey RJ (2014) Inducible loss of one Apc allele in Lrig1-expressing progenitor cells results in multiple distal colonic tumors with features of familial adenomatous polyposis. Am J Physiol Gastrointest Liver Physiol 307: G16-G23.

Powell AE, Wang Y, Li Y, Poulin EJ, Means AL, Washington MK, Higginbotham JN, Juchheim A, Prasad N, Levy SE, Guo Y, Shyr Y, Aronow BJ, Haigis KM, Franklin JL, Coffey RJ (2012) The Pan-ErbB negative regulator Lrig1 is an intestinal stem cell marker that functions as a tumor suppressor. Cell 149: 146-158.

Preston SL, Wong WM, Chan AOO, Poulsom R, Jeffery R, Goodlad RA, Mandir N, Elia G, Novelli M, Bodmer WF, Tomlinson IP, Wright NA (2003) Bottom-up histogenesis of colorectal adenomas: origin in the monocryptal adenoma and initial expansion by crypt fission. Cancer Res 63: 3819-3825.

Ritsma L, Ellenbroek SIJ, Zomer A, Snippert HJ, de Sauvage FJ, Simons BD, Clevers H, van Rheenen J (2014) Intestinal crypt homeostasis revealed at single-stem-cell level by in vivo live imaging. Nature 507: 362-365.

Roth S, Franken P, Sacchetti A, Kremer A, Anderson K, Sansom O, Fodde R (2012) Paneth cells in intestinal homeostasis and tissue injury. PLoS One 7: e38965.

Sadanandam A, Lyssiotis CA, Homicsko K, Collisson EA, Gibb WJ, Wullschleger S, Ostos LCG, Lannon WA, Grotzinger C, Del Rio M, Lhermitte B, Olshen AB, Wiedenmann B, Cantley LC, Gray JW, Hanahan D (2013) A colorectal cancer classification system that associates cellular phenotype and responses to therapy. Nat Med 19: 619-625.

Sangiorgi E, Capecchi MR (2008) Bmil is expressed in vivo in intestinal stem cells. Nat Genet 40: 915-920.

Sansom OJ, Reed KR, Hayes AJ, Ireland H, Brinkmann H, Newton IP, Batlle E, Simon-Assmann P, Clevers H, Nathke IS, Clarke AR, Winton DJ (2004) Loss of Apc in vivo immediately perturbs Wnt signaling, differentiation, and migration. Genes Dev 18: 1385-1390.

Sansom OJ, Näthke I (2013) Importance of the niche: Wnt signaling and stem cell plasticity in intestinal homeostasis and disease. In Molecular
Pathogenesis of Colorectal Cancer, Haigis KM (ed), pp 107-120. Springer: New York.

Schwitalla S, Fingerle AA, Cammareri P, Nebelsiek T, Göktuna SI, Ziegler PK, Canli O, Heijmans J, Huels DJ, Moreaux G, Rupec RA, Gerhard M, Schmid R, Barker N, Clevers H, Lang R, Neumann J, Kirchner T, Taketo MM, van den Brink GR, Sansom OJ, Arkan MC, Greten FR (2013) Intestinal tumorigenesis initiated by dedifferentiation and acquisition of stem-cell-like properties. Cell 152: 25-38.

Shih IM, Wang TL, Traverso G, Romans K, Hamilton SR, Ben-Sasson S, Kinzler KW, Vogelstein B (2001) Top-down morphogenesis of colorectal tumors. Proc Natl Acad Sci USA 98: 2640-2645.

Snippert HJ, van der Flier LG, Sato T, van Es JH, van den Born M, KroonVeenboer C, Barker N, Klein AM, van Rheenen J, Simons BD, Clevers H (2010) Intestinal crypt homeostasis results from neutral competition between symmetrically dividing Lgr5 stem cells. Cell 143: 134-144.

Snippert HJ, Schepers AG, Van Es JH, Simons BD, Clevers H (2014) Biased competition between Lgr5 intestinal stem cells driven by oncogenic mutation induces clonal expansion. EMBO Rep 15: 62-69.

Tian H, Biehs B, Warming S, Leong KG, Rangell L, Klein OD, de Sauvage FJ (2011) A reserve stem cell population in small intestine renders Lgr5positive cells dispensable. Nature 478: 255-259.

Van Es JH, Sato T, van de Wetering M, Lyubimova A, Yee Nee AN, Gregorieff A, Sasaki N, Zeinstra L, van den Born M, Korving J, ACM Martens, Barker N, van Oudenaarden A, Clevers H (2012) Dll1(+) secretory progenitor cells revert to stem cells upon crypt damage. Nat Cell Biol 14: 1099-1104.

Vermeulen L, Morrissey E, van der Heijden M, Nicholson AM, Sottoriva A, Buczacki S, Kemp R, Tavaré S, Winton DJ (2013) Defining stem cell dynamics in models of intestinal tumor initiation. Science 342: 995-998.

Vermeulen L, Snippert HJ (2014) Stem cell dynamics in homeostasis and cancer of the intestine. Nat Rev Cancer 14: 468-480.

Westphalen CB, Asfaha S, Hayakawa Y, Takemoto Y, Lukin DJ, Nuber AH, Brandtner A, Setlik W, Remotti H, Muley A, Chen X, May R, Houchen CW, Fox JG, Gershon MD, Quante M, Wang TC (2014) Long-lived intestinal tuft cells serve as colon cancer-initiating cells. J Clin Invest 124: 1283-1295.

Yatabe Y, Tavaré S, Shibata D (2001) Investigating stem cells in human colon by using methylation patterns. Proc Natl Acad Sci USA 98: 10839-10844.

Zhu L, Gibson P, Currle DS, Tong Y, Richardson RJ, Bayazitov IT, Poppleton H, Zakharenko S, Ellison DW, Gilbertson RJ (2009) Prominin 1 marks intestinal stem cells that are susceptible to neoplastic transformation. Nature 457: 603-607.

(c) (1) (2) This work is licensed under the Creative Commons (1) Attribution-Non-Commercial-Share Alike 4.0 International License. To view a copy of this license, visit http:// creativecommons.org/licenses/by-nc-sa/4.0/ 